\section{HEALTH PROMOTING EFFECTS OF A FAMILY FOCUSED CARE PROGRAMME IN A NORWEGIAN NEONATAL INTENSIVE CARE UNIT}

\author{
H. Wataker ${ }^{1}$, E. Nestaas ${ }^{1}$, A. Meberg ${ }^{1}$, S. Torp ${ }^{2}$ \\ ${ }^{1}$ Neonatal Intensive Care Unit, Vestfold Hospital \\ Trust, Tønsberg, '2Vestfold University, \\ Horten, Norway
}

Background and aims: Parental involvement in NICUs has become increasingly common. In Family Focused Care (FFC) intervention programmes, parents are encouraged to reside in the NICU together with their newborns, taking a more active part in the daily care. The aim of this study was to assess the impact from FFC on parental confidence and breastfeeding.

Methods: Parental confidence and breastfeeding rate were assessed for 31 mothers in a NICU providing FFC. Thirty mothers from a NICU where "traditional care" (TC) was provided served as controls. Data were collected using a selfadministered questionnaire one week prior to hospital discharge and by a telephone-interview three months after discharge.

Results: One week prior to hospital discharge, both groups reported similar satisfaction regarding information on medical issues and they were similarly satisfied with the support received from the staff. Mothers in the FFC group felt better informed in nursing issues and felt more confidence both in interpretation of the neonate regarding feeding issues and in taking care of the neonate during daytime, and they also reported a higher level of self-esteem $(p<0.05)$. At three months, there was a trend for more neonates in the FFC group being breastfed (70\% (FFC-group) vs $46 \%$ (TCgroup); $p=0.07$ ), and the mothers in the FFC group had a higher self-reported skill level regarding interpretation of the infant's cues and knowledge regarding breastfeeding $(p<0.05)$.

Conclusions: Family Focused Care (FFC) programmes in a NICU promoted parental confidence during the stay in the NICU and three months after discharge.

\section{PRE OPERATIVE PREPARATION BUNDLE OF CARE: LISTENING TO THE NEEDS OF THE PAEDIATRIC INTENSIVE CARE (PICU) PATIENT AND FAMILY}

\section{J.V. Ward}

\section{Paediatric Intensive Care, Evelina Children's Hospital, London, UK}

PICU, at the Evelina Children's Hospital, is a 20 bedded general and cardiac intensive care unit. We have a team of approximately 150 staff and promote open communication between staff, patients and families.

Feedback from some of our families indicated that at times, an inconsistent approach to preparation for a PICU admission was provided. A literature review was undertaken to explore the relevance and importance of preparation. Preparation was found to reduce anxiety, facilitate coping and improve recovery (Sutherland, 2003). Information giving resulted in a reduction in post operative nausea, pain and even has positive implications for a reduction in length of stay (Martin 1996).

With this in mind a 'preparation bundle' was developed including;

- A face to face meeting with the nursing team for the child and their family

- A guided tour of the clinical area, with and an opportunity to meet the staff.

- A family information booklet is provided.

- A checklist to gather information about the child and their individual needs

- A booklet using photographs and a storyboard prompt staff to discuss expectations of the child and family following surgery.

This care bundle has been well evaluated and changes suggested incorporated. Once well established the process will be audited and the findings reviewed.

We recognise that anxiety cannot be completely alleviated but by providing information and insight, a therapeutic relationship can be established to support a child and family during this stressful time. 